\title{
The impact of the 2006 Massachusetts health care reform law on spine surgery patient payer-mix status and age
}

\author{
Nicolas W. Villelli, MD, ${ }^{1}$ Hong Yan, BS, ${ }^{2}$ Jian Zou, PhD, ${ }^{2}$ and Nicholas M. Barbaro, MD ${ }^{1}$ \\ ${ }^{1}$ Goodman Campbell Brain and Spine, Department of Neurological Surgery, Indiana University School of Medicine, Indianapolis, \\ Indiana; and ${ }^{2}$ Department of Mathematical Sciences, Worcester Polytechnic Institute, Worcester, Massachusetts
}

\begin{abstract}
OBJECTIVE Several similarities exist between the Massachusetts health care reform law of 2006 and the Affordable Care Act (ACA). The authors' prior neurosurgical research showed a decrease in uninsured surgeries without a significant change in surgical volume after the Massachusetts reform. An analysis of the payer-mix status and the age of spine surgery patients, before and after the policy, should provide insight into the future impact of the ACA on spine surgery in the US.

METHODS Using the Massachusetts State Inpatient Database and spine ICD-9-CM procedure codes, the authors obtained demographic information on patients undergoing spine surgery between 2001 and 2012. Payer-mix status was assigned as Medicare, Medicaid, private insurance, uninsured, or other, which included government-funded programs and workers' compensation. A comparison of the payer-mix status and patient age, both before and after the policy, was performed. The New York State data were used as a control.
\end{abstract}

RESULTS The authors analyzed 81,821 spine surgeries performed in Massachusetts and 248,757 in New York. After 2008 , there was a decrease in uninsured and private insurance spine surgeries, with a subsequent increase in the Medicare and "other" categories for Massachusetts. Medicaid case numbers did not change. This correlated to an increase in surgeries performed in the age group of patients 65-84 years old, with a decrease in surgeries for those 18-44 years old. New York showed an increase in all insurance categories and all adult age groups.

CONCLUSIONS After the Massachusetts reform, spine surgery decreased in private insurance and uninsured categories, with the majority of these surgeries transitioning to Medicare. Moreover, individuals who were younger than 65 years did not show an increase in spine surgeries, despite having greater access to health insurance. In a health care system that requires insurance, the decrease in private insurance is primarily due to an increasing elderly population. The Massachusetts model continues to show that this type of policy is not causing extreme shifts in the payer mix, and suggests that spine surgery will continue to thrive in the current US health care system.

https://thejns.org/doi/abs/10.3171/2017.4.SPINE161141

KEY WORDS Patient Protection and Affordable Care Act; Massachusetts health care reform law; uninsured patients; neurosurgical procedures; physician compensation; payer-mix status; spine surgery

$\mathrm{W}$ ITH the passage of the Affordable Care Act (ACA) in 2009, significant debate has developed as to the financial implications of this policy. This bill has many similarities to the Massachusetts health care reform law of 2006, including subsidies for lower-income families, individual and business mandates, and state-based exchanges. ${ }^{1}$ Because of these parallels, prior research has used Massachusetts as a predictor of the ACA's impact on the future of the US health care system..$^{3,5,8,10}$ Our prior analysis showed that neurosurgical procedure volume and rate of volume change were relatively unchanged after the health care reform in Massachusetts. ${ }^{10}$ Although no significant change in volume occurred after the policy, there was a significant decrease in uninsured surgeries for all major neurosurgical subspecialties after the reform. These results showed that more procedures were performed on insured individuals, and thus on those who could provide reimbursement for their surgeries. Despite this potential benefit to reimbursement, the complete impact of this policy remains unclear. 
To better understand the financial effect of the Massachusetts reform, it is important to appreciate the changes in the payer mix that occurred after the policy was implemented, as well as shifts in age of the spine surgery population. Prior research in orthopedic surgery has shown minimal change in the payer mix for joint replacement surgeries after the Massachusetts reform, ${ }^{7}$ but to our knowledge, this is the first study to analyze any payer-mix trends in spine surgery after the Massachusetts reform. This study uses Massachusetts as a model to better understand the future impact of the ACA on the payer-mix status and on the age of patients who undergo spine surgery in the US.

\section{Methods}

The State Inpatient Databases for Massachusetts and New York (the control state) were used to obtain the payer status and age of all spine surgery patients who underwent the procedure between 2001 and 2012. This was done using the HCUPnet online service, which is a segment of the Healthcare Cost and Utilization Project. This resource provides demographic information on all hospital discharges within each state. Prior research has used New York as a control, given its similar geographic location to Massachusetts, and also because it offers annual data for all the years analyzed in our study. ${ }^{3,10}$

The payer status options provided in the inpatient database are Medicare, Medicaid, private insurance, uninsured, or other. The "other" category included workers' compensation; TRICARE/CHAMPUS (now TRICARE, formerly known as the Civilian Health and Medical Program of the Uniformed Services); CHAMPVA (Civilian Health and Medical Program of the Department of Veterans Affairs); Title V; and Preferred Provider Organizations (PPOs). The age of patients is provided in the following categories: < 1 year old, 1-17, 18-44, 45-64, $65-84$, and $\geq 85$ years old. Table 1 shows an all-inclusive list of ICD-9-CM procedure codes used for our spine surgery analysis. These codes have been used in prior studies analyzing trends in neurosurgery. ${ }^{6,10}$ Annual data on payer status and patient age from 2001 to 2012 was obtained using the following State Inpatient Database protocol: 1) specific procedures by ICD-9-CM code, and 2) all listed procedures.

All data were controlled for differences in population by using a surgery/100,000 value. The annual population for both Massachusetts and New York was calculated using the 2000 and 2010 US census state populations (www. census.gov). From these 2 data points a linear relationship was assumed, to calculate the annual state population for both Massachusetts and New York from 2001 to 2012 (https://www.census.gov/quickfacts/table/RHI105210/36).

For the statistical analysis, the data were divided into 2 groups. Group 1 consisted of surgeries during the calendar years 2001-2007, and Group 2 were surgeries during the calendar years 2008-2012. To test whether there were significant differences between the 2 groups, ANCOVA was used to analyze both the slopes and intercepts of the regression lines.

To test whether Group 1 and Group 2 had different slopes, we used the following formulas. Full model, $Y_{i j}=$
TABLE 1. The ICD-9-CM procedure codes for all spine surgeries analyzed that were performed in Massachusetts and New York between 2001 and 2012

\begin{tabular}{|c|c|}
\hline Code & Description \\
\hline 81.03 & Other cervical fusion, posterior technique \\
\hline 81.05 & Dorsal and dorsolumbar fusion, posterior technique \\
\hline 81.08 & Lumbar and lumbosacral fusion, posterior technique \\
\hline 81.33 & Refusion of other cervical spine, posterior technique \\
\hline 81.35 & Refusion of dorsal and dorsolumbar spine, posterior technique \\
\hline 81.38 & Refusion of lumbar and lumbosacral spine, posterior technique \\
\hline 81.02 & Other cervical fusion, anterior technique \\
\hline 81.04 & Dorsal and dorsolumbar fusion, anterior technique \\
\hline 81.06 & Lumbar and lumbosacral fusion, anterior technique \\
\hline 81.32 & Refusion of other cervical spine, anterior technique \\
\hline 81.34 & Refusion of dorsal and dorsolumbar spine, anterior technique \\
\hline 81.36 & Refusion of lumbar and lumbosacral spine, anterior technique \\
\hline 81.07 & $\begin{array}{l}\text { Lumbar and lumbosacral fusion, lateral transverse process } \\
\text { technique }\end{array}$ \\
\hline 81.01 & Atlas-axis spinal fusion \\
\hline 81.31 & Refusion of atlas-axis spine \\
\hline 81.37 & $\begin{array}{l}\text { Refusion of lumbar and lumbosacral spine, lateral transverse } \\
\text { process technique }\end{array}$ \\
\hline 81.00 & Spinal fusion, not otherwise specified \\
\hline 81.39 & Refusion of spine, not elsewhere classified \\
\hline
\end{tabular}

$\mu+\tau l_{i j}+y x_{i j}+\beta x_{i j} I_{i j}+\Sigma_{i}$; and reduced model, $Y_{i j}=\mu+\tau l_{i j}$ $+y x_{i j}+\Sigma_{i}$, where $\mu$ is an overall mean; $\tau$ is the fixed treatment effects of Group $1 ; x_{i j}$ is the centered data of the $j$ th observation in Group 1; and $I_{i j}$ is an indicator and $I_{i j}=1$ if $x_{i j}$ is in Group 1-otherwise, $I_{i j}=-1$.

If the coefficient of the interaction was significant $(\beta \neq$ 0 ), there were significant differences between the slopes of the regression lines of the 2 groups, and thus a statistical difference between the 2 groups. If the coefficient of the interaction was not significant $(\beta=0)$, a difference of intercepts was then tested, as follows. Full model, $Y_{i j}=\mu+$ $\tau l_{i j}+y x_{i j}+\Sigma_{i}$; and reduced model, $Y_{i j}=\mu+y x_{i j}+\Sigma_{i}$.

If the coefficient of the indicator was significant $(\tau \neq 0)$, there were significant differences between the intercepts of the regression lines of the 2 groups, and thus significant differences between the 2 groups. Otherwise, we could not reject the null hypothesis that payer mix or age of the 2 groups was the same.

There was a small subset of data (55 patients) in which the payer mix or patient age was unknown. This accounted for only $0.07 \%$ of the total surgeries analyzed. A popular method when dealing with missing data is to reproduce the data used into existing patterns. This was done by increasing the weight of the responding data to use as a representation of the missing data. For Medicare, Medicaid, private insurance, uninsured, and "other," the adjustment percentage was as follows: adjusted percentage $=$ initial percentage $/ 1$ - percentage of missing data. The adjusted cases $/ 100,000$ is the product of total cases and the corresponding adjusted percentage with respect to each category. 


\section{Results}

The demographic breakdown of all spine surgeries performed in Massachusetts and New York between 2001 and 2012 is displayed in Table 2. During the time period studied, there were 81,821 spine surgeries in Massachusetts and 248,757 in New York. The age breakdown of the Massachusetts population was 3666 (4.48\%) for 0-17 years; $21,769(26.61 \%)$ for $18-44$ years; 37,306 $(45.59 \%)$ for 45-64 years; 18,217 (22.26\%) for 65-84 years; and $856(1.05 \%)$ for $\geq 85$ years. In New York the age breakdown was 11,181 (4.49\%) for 0-17 years; 67,829 (27.27\%) for 18-44 years; 116,779 (46.95\%) for 45-64 years; 51,051 $(20.52 \%)$ for 65-84 years; and $1909(0.77 \%)$ for $\geq 85$ years. From 2000 to 2010, the Massachusetts population of individuals 65 years or older increased from $13.5 \%$ to $13.7 \%$, while New York showed an increase in this same age group from $12.8 \%$ to $13.5 \%$. In Massachusetts, 38,909 $(47.55 \%)$ of spine surgery patients were male and 42,908 $(52.44 \%)$ were female. In New York, 117,100 (47.07\%) were male and 131,654 (52.93\%) were female. There was a small subset of data for which the age or sex was unknown; in Massachusetts this was 11 (0.01\%), and in New York it was $11(0.004 \%)$. The payer status was also unknown in Massachusetts for $55(0.07 \%)$ surgeries and in New York for $0(0 \%)$ surgeries.

The upper image in Fig. 1 shows the payer-mix breakdown for all spine surgeries performed in Massachusetts between 2001 and 2012. This shows that after 2007, there was a decrease in both uninsured (test slope $p=0.0625$, test intercept $\mathrm{p}=0.0095$ ) and privately insured (test slope $\mathrm{p}=$ 0.0003 ) surgeries, with a subsequent increase in Medicare (test slope $\mathrm{p}=0.0005$ ) and "other" (test slope $\mathrm{p}=0.1470$, test intercept $\mathrm{p}=0.032$ ) categories. Medicaid-financed spine surgeries remained unchanged throughout the time period studied. The lower image in Fig. 1 shows the payermix breakdown for all spine surgeries performed in New York between 2001 and 2012. This graph shows the relentless increase in all payer groups, including Medicare (test slope $\mathrm{p}=0.0062$ ), Medicaid (test slope $\mathrm{p}=0.0073$ ), private insurance (test slope $\mathrm{p}=0.0161$ ), uninsured (test slope $\mathrm{p}=$

TABLE 2. Demographic data for patients who underwent spine surgery in Massachusetts and New York between 2001 and 2012

\begin{tabular}{lcc}
\hline & \multicolumn{2}{c}{ Total Cases (\%) } \\
\cline { 2 - 3 } \multicolumn{1}{c}{ Variable } & $\begin{array}{c}\text { Massachusetts; } \\
\mathrm{n}=81,821\end{array}$ & $\begin{array}{c}\text { New York; } \\
\mathrm{n}=248,757\end{array}$ \\
\hline Age in yrs & $3,666(4.48)$ & $11,181(4.49)$ \\
\hline $0-17$ & $21,769(26.61)$ & $67,829(27.27)$ \\
\hline $18-44$ & $37,306(45.59)$ & $116,779(46.95)$ \\
\hline $45-64$ & $18,217(22.26)$ & $51,051(20.52)$ \\
\hline $65-84$ & $856(1.05)$ & $1,909(0.77)$ \\
\hline$\geq 85$ & & \\
\hline Sex & $38,909(47.55)$ & $117,100(47.07)$ \\
\hline Male & $42,908(52.44)$ & $131,654(52.93)$ \\
\hline Female & $11(0.01)$ & $11(0.004)$ \\
\hline Missing age or sex data & $55(0.07)$ & $0(0)$ \\
\hline Missing insurance status data & \multicolumn{2}{c}{}
\end{tabular}

0.9400 , test intercept $\mathrm{p}=0.0445$ ), and "other" (test slope $\mathrm{p}$ $=0.0002$ ) after 2007 .

The upper image in Fig. 2 shows the age breakdown for all spine surgeries performed in Massachusetts between 2001 and 2012. There was an increase in spine surgeries performed on individuals 65-84 years old (test slope $\mathrm{p}=0.0001$ ) and a decrease in spine surgeries on 18- to 44-year-olds (test slope $\mathrm{p}=0.0004$ ) after 2007. The age groups $0-17,45-64$, and $\geq 85$ years did not show a change in surgery volume after 2007. The lower image in Fig. 2 shows the age breakdown for spine surgeries performed in New York between 2001 and 2012. This shows an increase in spine surgeries for those aged 18-44, 45-64, and 65-84 years after 2007. The volume of spine surgeries in the age groups 0-17 and $\geq 85$ years did not change after 2007 .

\section{Discussion}

Massachusetts has been extensively used as a model to predict the impact of the ACA on the US health care system. ${ }^{3,5,8,10}$ The similarities in the policies allow for observations in a health care system that mandates that individuals obtain health insurance. Prior research has shown that, on the whole, neurosurgical case volume or rate of volume change did not vary after the Massachusetts health care reform. ${ }^{10}$ Despite a constant in procedure volume, uninsured surgeries decreased for all subspecialties in neurosurgery. To better understand the effect of this policy, it is important to analyze the manner in which uninsured surgeries have transitioned to insured surgeries. As the number of spine surgeries continues to increase within neurosurgery, there is an opportunity to analyze payermix changes within a growing subspecialty of the field. To our knowledge, this is the first study to analyze the payermix changes of spine surgery in Massachusetts after its health care reform.

The results of our study showed the transitions in the payer-mix status of spine surgery patients in Massachusetts after 2008. There was a decrease in privately insured and uninsured patients. This was compensated by an increase in both Medicare and the "other" category of payers. The "other" category, which includes workers' compensation, TRICARE/CHAMPUS, CHAMPVA, Title V, and PPOs, accounted for only $9.4 \%$ of the surgeries performed between 2008 and 2012. Medicare surgeries, however, accounted for $31.5 \%$ of all spine surgeries performed between 2008 and 2012, suggesting that the decrease in privately insured surgeries occurred primarily as a result of a transition to Medicare-covered surgeries. This differed from the control state, New York, in that all payer categories increased between 2008 and 2012. New York Medicare-covered surgeries accounted for only $13.1 \%$ of all surgeries after 2008, and the "other" group was $8.9 \%$.

These results suggest that the primary shift away from the private and uninsured surgery decrease was an increase in Medicare-covered spine surgeries after the Massachusetts reform. Increases in Medicare surgeries have also been observed in orthopedic surgery, where Nwachukwu et al. found national increases in both total knee and total hip replacements for Medicare patients between 2005 and 2011. ${ }^{9}$ Very little research, however, has identi- 


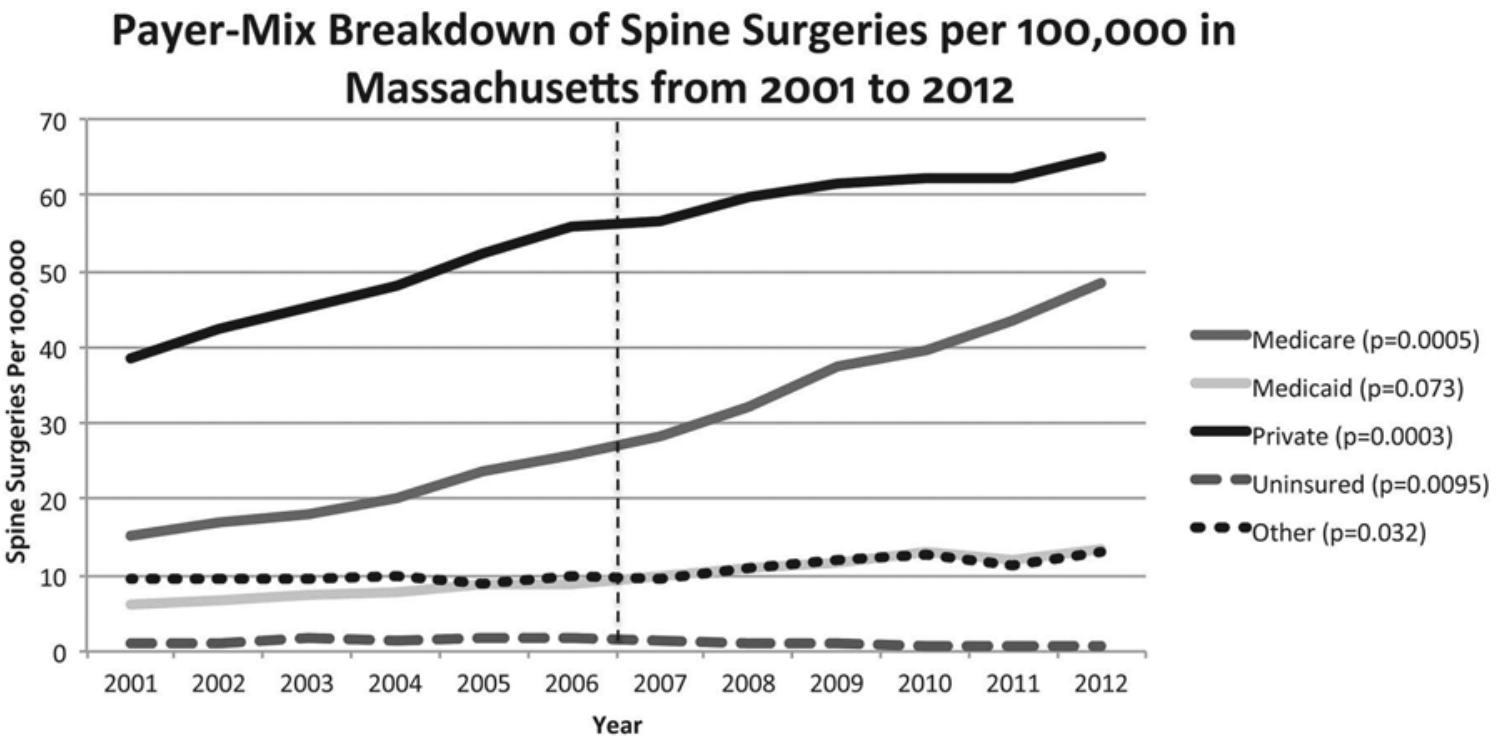

\section{Payer-Mix Breakdown of Spine Surgeries per 100,000 in} New York from 2001 to 2012

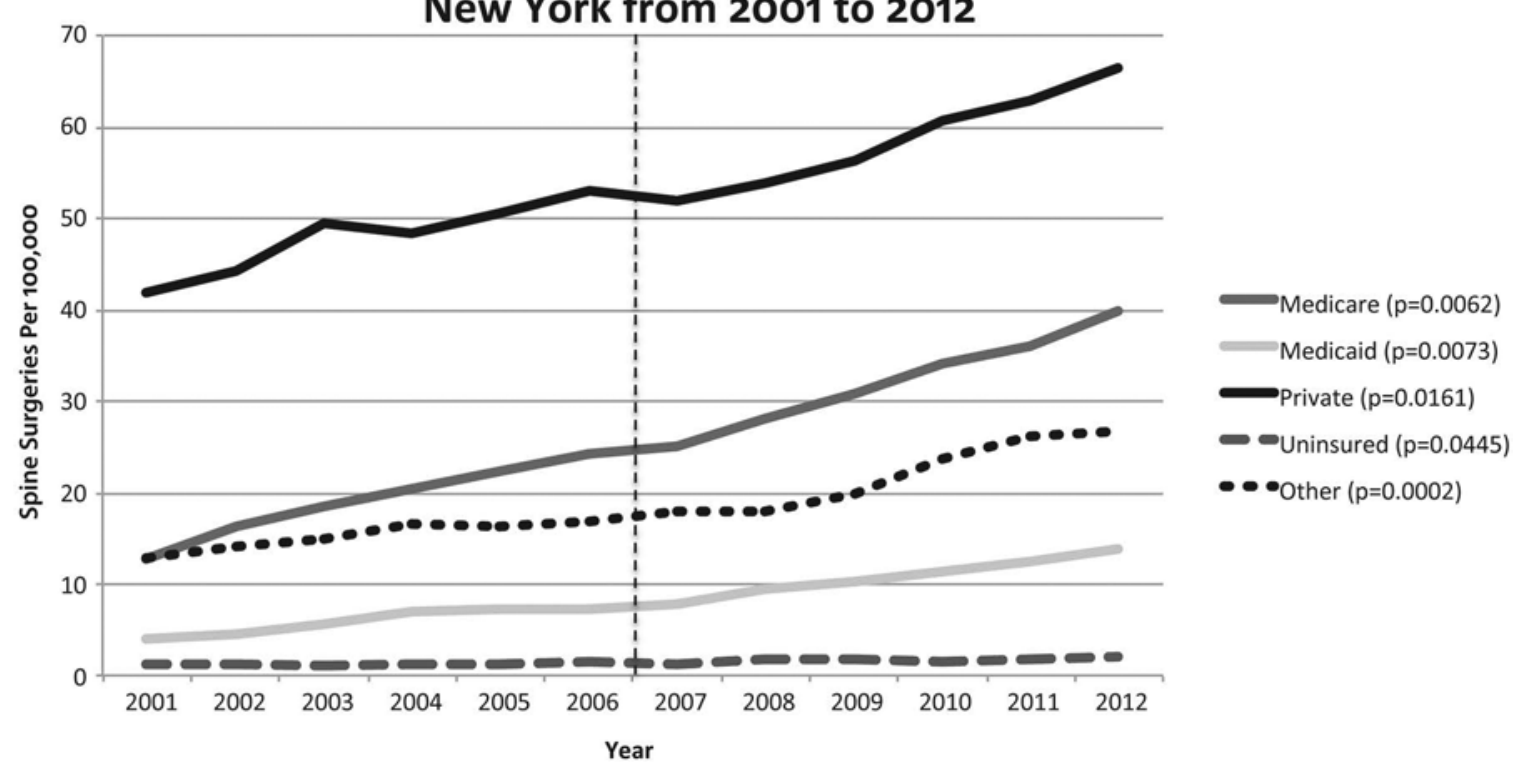

FIG. 1. Graphs showing payer-mix breakdown for all spine surgeries performed in Massachusetts (upper) and New York (lower) between 2001 and 2012.

fied Medicare surgery changes within Massachusetts. In addition to understanding the payer-mix changes within Massachusetts, it is important to analyze the shifts in the age of spine surgery patients. Our data show that in Massachusetts after the reform, spine surgeries increased only for individuals 65-84 years old, thus affecting the primary age group of individuals on Medicare. This is a logical change and explains the decrease in privately insured patients as the population aged. Our data suggest that in a mandated insurance system, the primary driver in decreased privately insured spine surgeries is the transitioning of the aging population to Medicare.

An important component to this study is an analysis of the changes that occurred in Medicaid-covered surgeries after implementation of the policy. Our results show no significant change in Medicaid-financed spine surgeries after the Massachusetts reform. There have been similar results reported in other specialties. Earp et al. showed no change in Medicaid-financed orthopedic hand surgeries after the passage of the Massachusetts policy, but did demonstrate a decrease in uninsured procedures, with a subsequent increase in insured surgeries. ${ }^{2}$ This finding is consistent with our age analysis. Medicaid is available to low-income individuals younger than 65 years. Our age analysis found a decrease in surgeries for those 18-44 years old and no change for those 0-17 and 45-64 years old. Other studies have analyzed the age of surgery patients in Massachusetts. Ellimoottil et al. also showed a decrease in urologi- 

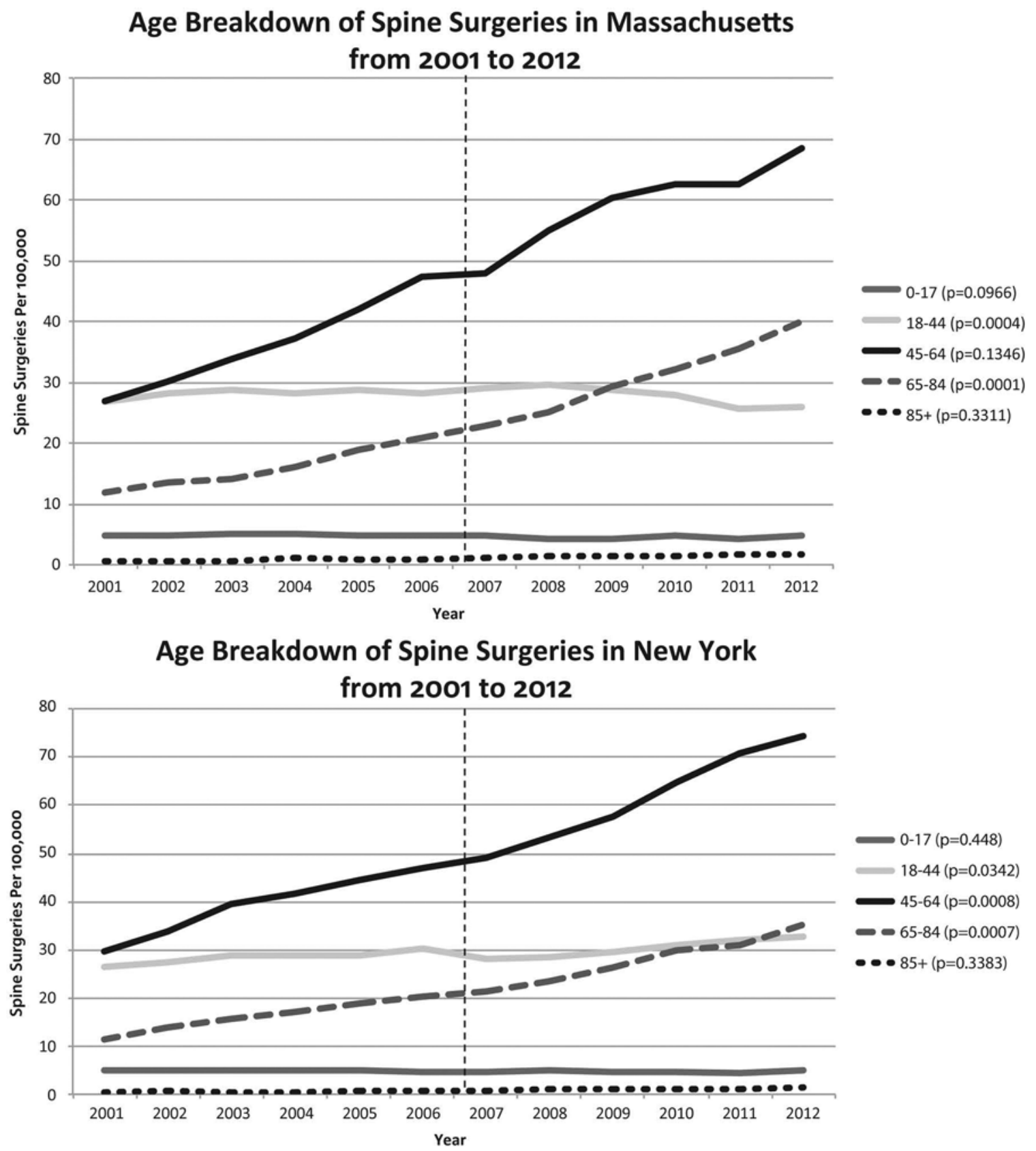

FIG. 2. Graphs showing age breakdown for all spine surgeries performed in Massachusetts (upper) and New York (lower) between 2001 and 2012.

cal surgeries performed in those between 19 and 40 years of age after the Massachusetts reform. ${ }^{4}$ These results suggest that despite the younger generation having more access to health insurance, there has not been an increase in surgeries for the Medicaid and younger populations.

Our study has several limitations, the first of which is the fact that spine surgery is classically more common in the aging population, making it difficult to completely understand the effect of mandated insurance on younger people. Despite this age bias, our control state, New York, did show an increase in spine surgeries performed in younger individuals, in both the 18- to 44-year-old and the 45- to 64-year-old groups, confirming that there was a true change in the age of spine surgery patients due to the policy change in Massachusetts. Another limitation to extrapolating observations made in Massachusetts to the national health care system is that the demographics of Massachusetts differ from national averages. This is most notable in both the racial makeup of the state and the average household income. The national Caucasian average was $77.2 \%$ in the 2010 census, compared with Massachusetts at $83.2 \%$ (https://www.census.gov/quickfacts/table/ RHI105210/25). Moreover, both African American (8.1\% vs $13.2 \%)$ and Hispanic (10.5\% vs $17.1 \%$ ) populations 
were lower in Massachusetts than national averages in the 2010 census. In addition to the racial differences seen in Massachusetts, the median income level is also higher in this state $(\$ 66,866)$ compared with the national average $(\$ 53,046)$. These demographic differences make extrapolation of national health care trends difficult. Despite these differences, however, Massachusetts is the only state to use a health care system similar to the ACA, and thus provides the most comparable model to observe trends in a health care system that mandates insurance.

Concerns regarding the financial impact of the ACA on medicine continue to dominate the national discussion. Objective data have shown that in a health care system that mandates insurance, surgical procedures continue to show positive outcomes. Prior research supports increases in inpatient procedures for lower- and medium-income populations, decreases in racial disparities for minimally invasive surgeries, and no significant change in case volume for neurosurgical procedures. ${ }^{3,8,10}$ This study has added to the ongoing analysis of the Massachusetts health care reform. Within spine surgery, the primary shift of the payer mix can be explained by the aging population transitioning from privately insured and uninsured status to Medicare. Further research is needed to understand the impact of the ACA on procedure reimbursement rates. A decrease in uninsured surgeries with a subsequent increase in Medicare implies a theoretical increase in reimbursement. A counterbalance to this is the decrease in private insurance of the aging population. It is unclear whether the increase in Medicare-covered surgeries will financially compensate for the decrease in privately insured spine surgeries.

\section{Conclusions}

Using Massachusetts as a model for the ACA, this study has established that the primary shift in the payer mix for spine surgery patients is due to the aging population transitioning to Medicare. This change is expected given an increasing elderly population, and is not a direct effect of mandated health insurance. This analysis continues to support the conclusion that a health care system that requires insurance does not have significant negative impacts on access to health care or reimbursements to physicians.

\section{References}

1. Burdett G: Romneycare vs. Obamacare: key similarities \& differences. CBS Boston. November 13, 2013. (http://boston. cbslocal.com/2013/11/13/romneycare-vs-obamacare-keysimilarities-differences/) [Accessed May 11, 2017]
2. Earp BE, Louie D, Blazar P: The impact of Massachusetts health care reform on an orthopedic hand service. J Hand Surg Am 38:2212-2217, 2013

3. Ellimoottil C, Miller S, Ayanian JZ, Miller DC: Effect of insurance expansion on utilization of inpatient surgery. JAMA Surg 149:829-836, 2014

4. Ellimoottil C, Miller S, Wei JT, Miller DC: Anticipating the impact of insurance expansion on inpatient urological surgery. Urol Pract 1:134-140, 2014

5. Hanchate AD, Lasser KE, Kapoor A, Rosen J, McCormick D, D'Amore MM, et al: Massachusetts reform and disparities in inpatient care utilization. Med Care 50:569-577, 2012

6. Hughey AB, Lesniak MS, Ansari SA, Roth S: What will anesthesiologists be anesthetizing? Trends in neurosurgical procedure usage. Anesth Analg 110:1686-1697, 2010

7. Kurtz SM, Lau E, Ong KL, Katz JN, Bozic KJ: Universal health insurance coverage in Massachusetts did not change the trajectory of arthroplasty use or costs. Clin Orthop Relat Res 474:1090-1098, 2016

8. Loehrer AP, Song Z, Auchincloss HG, Hutter MM: Massachusetts health care reform and reduced racial disparities in minimally invasive surgery. JAMA Surg 148:1116-1122, 2013

9. Nwachukwu BU, McCormick F, Provencher MT, Roche M, Rubash HE: A comprehensive analysis of Medicare trends in utilization and hospital economics for total knee and hip arthroplasty from 2005 to 2011 . J Arthroplasty 30:15-18, 2015

10. Villelli NW, Das R, Yan H, Huff W, Zou J, Barbaro NM: Impact of the 2006 Massachusetts health care insurance reform on neurosurgical procedures and patient insurance status. J Neurosurg 126:167-174, 2017

\section{Disclosures}

The authors report no conflict of interest concerning the materials or methods used in this study or the findings specified in this paper.

\section{Author Contributions}

Conception and design: all authors. Acquisition of data: all authors. Analysis and interpretation of data: all authors. Drafting the article: all authors. Critically revising the article: Villelli, Barbaro. Reviewed submitted version of manuscript: all authors. Approved the final version of the manuscript on behalf of all authors: Villelli. Statistical analysis: all authors. Administrative/ technical/material support: all authors. Study supervision: Villelli, Zou, Barbaro.

\section{Correspondence}

Nicolas W. Villelli, Department of Neurological Surgery, Goodman Campbell Brain and Spine, Indiana University School of Medicine, 355 W 16th St., GH 5100, Indianapolis, IN 46202. email: nwvillel@iupui.edu. 